\title{
Effects of LSD-25 on bar-pressing behavior in the hooded rat'
}

\begin{abstract}
Thirty-six male hooded rats were used to study the dose-response relation between LSD-25 and foodmotivated operant behavior. It was found that LSD-25 exerted a deleterious effect on this behavior over a wide range of doses and that the resultant doseresponse function was negatively accelerated.

\section{Introduction}

Despite the large number of psychopharmacological studies in which d-lysergic acid diethylamide (LSD-25) is used, very few studies have concentrated on the dose-response relation for this drug. Most workers have been content to investigate the behavioral effects of a few arbitrarily selected doses, and have generally reported that LSD-25 produces decremental operant performance (Winter \& Flataker, 1956). Some investigators, however, have reported behavioral facilitation with LSD-25 (Hamilton, 1960; Jarrard, 1963) and Jarrard (1963) has suggested that LSD-25 may have a dose-dependent bi-modal effect on behavior. It thus seems clear that detailed investigation of the behavioral effects of this drug over a wide range of doses is called for. The present investigation was a study of this dose-response relation for the hooded rat. Two experimental procedures were employed, one in which the animals served as their own controls and one in which a matched-groups technique was used.
\end{abstract}

\section{Subjects}

Ss were 36 male hooded rats of the Royal Victoria Hospital strain. The $12 \mathrm{Ss}$ in experiment 1 were approximately 140 days of age when drug injections were begun, while the $24 \mathrm{Ss}$ in experiment 2 were approximately 117 days of age at the beginning of injections.

\section{Apparatus}

The apparatus consisted of six Skinner-type boxes which provided food reinforcement $(45 \mathrm{mg}$ Noyes Co. pellets) for bar-pressing behavior on an aperiodic reinforcement schedule (VI 1 min.).

\section{Procedure}

Experiment 1. The 12 Ss used in experiment 1 started training in the Skinner-boxes at approximately 82 days of age. Each $\mathrm{S}$ was tested at the same time every day for $1 \mathrm{hr}$. Immediately following each test session, Ss were returned to their home cages for $1 / 2 \mathrm{hr}$. Training continued for 58 days, by which time all Ss had reached relatively stable rates of bar-pressing. Intraperitoneal injections of LSD-25 were then begun. Each S served as his own control and received a total of five injections of
LSD-25 (each injection at a different dose level) plus one control injection of sterile physiological saline. A 6 by 6 Latin square rotation of dose levels was employed. Six Ss were tested on low doses $(0.015,0.065,0.115$, 0.165 , and $0.215 \mathrm{mg} / \mathrm{kg}$ ) and the six others were tested on high doses $(0.120,0.215,0.310,0.405$, and 0.500 $\mathrm{mg} / \mathrm{kg})$. All solutions were diluted with distilled water such that a constant volume of $1.5 \mathrm{cc}$ was injected at each dose level. Injections were given immediately prior to the beginning of the $1 \mathrm{hr}$. test session. Two days with no injections were interspersed between each injection day.

Experiment 2. The training procedure of experiment 2 was identical with that of experiment 1 except that the training continued for only 35 days before injections were begun. By the end of this 35 day period, all Ss had reached relatively stable rates of bar-pressing. Ss were then divided into four equal groups, matched for weight and response rate. On the 36th day after the beginning of training, Ss were given intraperitoneal injections of LSD-25 or sterile physiological saline. The first group received $0.20 \mathrm{mg} / \mathrm{kg} \mathrm{LSD}-25$, the second received 0.10 $\mathrm{mg} / \mathrm{kg}$ LSD-25, the third received $0.05 \mathrm{mg} / \mathrm{kg} \mathrm{LSD}-25$, and the fourth received saline. Injections were given immediately prior to the beginning of the $1 \mathrm{hr}$. test session. Seventeen days with no injections then followed for all groups. On the 52nd day after the beginning of the initial training, Ss in two of the four groups were reinjected with $0.10 \mathrm{mg} / \mathrm{kg} \mathrm{LSD-25}$ and tested.

\section{Results and Discussion}

The results of both experiments are shown in Fig. 1. High doses of LSD-25 were found to have a markedly deleterious effect on bar-pressing rates while low doses had a lesser, though still marked, effect. Analyses of variance performed on the data from experiment 1 yielded significant dosage effects for both the high dose group $(F=9.89, d f=5 / 20, p<.001)$ and the low dose group $(\mathrm{F}=6.32, \mathrm{df}=5 / 20, \mathrm{p}<.005)$. Analysis of co-variance of the data from experiment 2 (day no. 36) also yielded a signficant dosage effect $(F=7.02$, $\mathrm{df}=3 / 18, \mathrm{p}<.005)$. It is thus clear that LSD-25 affects food-motivated behavior over a wide range of doses, and that the degree of effect varies with the dose. Furthermore, inspection of Fig. 1 strongly suggests that the resultant dose-response function is negatively accelerated.

Inspection of cumulative records indicated that the peak effect of the drug occurred typically during the first $30 \mathrm{~min}$. after injection regardless of dose level, 


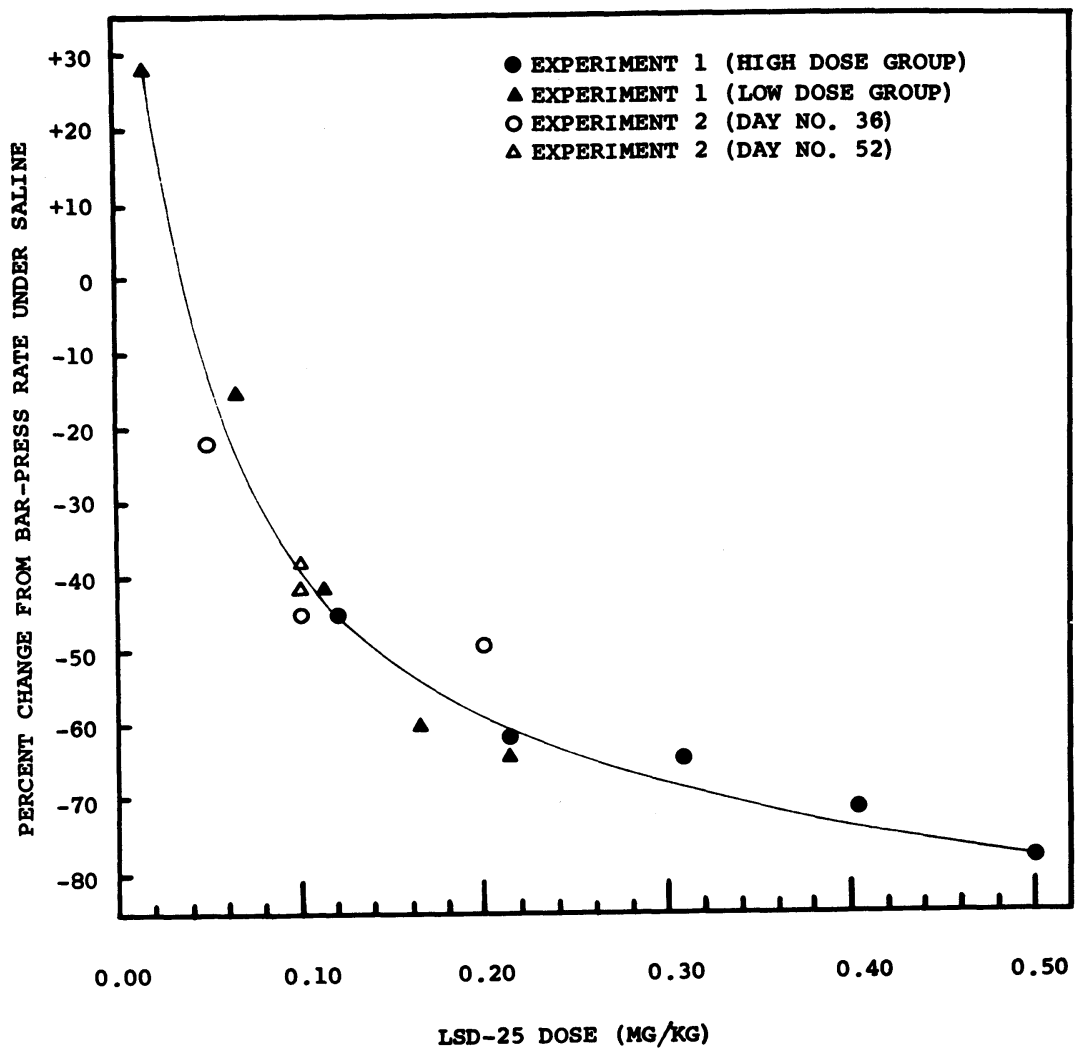

Fig. 1. Dose-response relation between LSD-25 and food-motivated bar-pressing behavior.

and that the onset of drug effects was very rapid for all dose levels; most animals suffered noticeable impairment of operant behavior within 5 min. after injection.

The present data do not confirm the findings of those investigators who have reported behavioral facilitation or stimulation with low doses of LSD-25 (Jarrard, 1963); the difference in the present study between the effects of $0.015 \mathrm{mg} / \mathrm{kg} \mathrm{LSD-25}$ and saline did not reach statistical significance $(t=0.86)$.

Thus, the present data do not support any bi-phasic or bi-modal theory of LSD-25 action. They do, however, indicate that LSD-25 has a deleterious effect on food- motivated operant behavior, that increased dosages have increased effects, and that the behavioral doseresponse function of this drug is negatively accelerated.

\section{References}

Hamilton, C. L. Effects of LSD-25 and amphetamine on a running response in the rat. Arch. gen. Psychiat., 1960, 2, 104-109. Jarrard, L. E. Effects of d-lysergic acid diethylamide on operant behavior in the rat. Psychopharmacologia, 1963, 5, 39-46.

Winter, C. A., \& Flataker, L. Effects of lysergic acid diethylamide upon performance of trained rats. Proc. Soc. Exp. Biol. Med., $1956,92,285-289$.

\section{Note}

1. This research was supported, in part, by United States Public Health Service Predoctoral Fellowship No. 1-F1-MH-23453-01 from the National Institute of Mental Health. 